\begin{tabular}{l|l} 
& North \\
Working Paper Series, Paper No. 09-08 & American \\
& Association of \\
Sports \\
Economists
\end{tabular}

\title{
The Economic Consequences of Foreigner Rules in National Sports Leagues
}

\author{
Markus Lang ${ }^{\dagger}$, Alexander Rathke ${ }^{\dagger \dagger}$ and Marco Runkel ${ }^{\dagger \dagger}$
}

June 2009

\begin{abstract}
This paper provides a contest model of a professional team sports league and analyzes the impact of a restriction on foreign players. It shows that a league with binding restrictions on foreign talent for all clubs is more balanced than a league without binding restrictions on foreign talent. Moreover, the wage level of domestic (foreign) talent is higher (lower) in a league with a binding restriction on foreign players. Finally, a tighter restriction on foreign players increases profits of all clubs.
\end{abstract}

\section{JEL Classification Codes: L83}

Keywords: Team Sports Leagues, UEFA's Homegrown Rule, FIFA's 6+5 Rule, Competitive Balance, Player Salaries

We gratefully acknowledge financial support provided by the Swiss National Science Foundation (SNSF research project no. 105270) and the research fund of the University of Zurich.

'Institute for Strategy and Business Economics, University of Zurich, Plattenstrasse 14 CH-8032 Zurich, Switzerland, Phone: +41 (0) 4463453 17, Fax: +41 (0) 4463453 01, markus.lang@isu.uzh.ch

${ }^{\dagger}$ Institute for Empirical Research in Economics, University of Zurich, Winterthurerstrasse 30, 8006 Zurich, Switzerland, Phone +41 (0)44 63435 69, Fax +41 (0)44 63435 99, rathke@iew.unizh.ch

††Faculty of Economics and Management, University of Magdeburg, P.O. Box 4120, 39016 Magdeburg, Germany. marco.runkel@ovgu.de 


\section{INTRODUCTION}

Running a financially healthy and balanced national sports league is among the central prerequisites for attracting the right to host an international mega-event like the FIFA ${ }^{1}$ World Cup or the UEFA ${ }^{2}$ European Football Championship. A successful league guarantees that the required infrastructure (e.g., stadiums, etc.) is provided. Moreover, a strong and balanced national sports league that fosters the strength of the national team is crucial for staging a successful mega-event because the economic outcome of the mega-event is heavily influenced by the sporting success of the home team. For example, Domen et al. (2006) show that the outcome of the 2006 World Cup strongly affected individuals' perceptions about economic prospects. If the German team had reached the final at the 2006 World Cup, Raetzel and Weiman (2006) estimate that the accumulated positive welfare effects would have been 747 million Euros. Heyne et al. (2007) show significant ex-post increase in valuation of the 2006 World Cup, which they attribute to the World Cup being an experience good. On the one hand, this finding maybe due to the unusually beneficial weather conditions, but on the other hand, it also reflects the (unexpected) success of the German team. ${ }^{3}$

Therefore, the successful hosting of a mega-event hinges on a solid foundation of a financially healthy and balanced domestic league. In the last two decades, however, increasing financial disparities and spiralling wages have become well-known problems in the European football leagues. Many European football clubs face serious financial problems. Some even went bankrupt. Restrictions on foreign players can help to alleviate these problems because foreign player restrictions may promote competitive balance while strengthening the financial situation of small clubs.

In December 1995, the European Court of Justice issued the famous Bosman verdict abolishing not only the existing transfer system but also the so-called "3+2 Rule," which restricted the number of foreign players a club may field. Since then, the proportion of foreign players has significantly increased in European professional football. For example, the percentage of foreign players in the English Premier League rose from 31 percent in the 1995-96 season up to 56.3 percent in the 2002-03 season. A similar trend can be observed in all Big Five Leagues. In the French Ligue 1, the percentage of foreign players rose from 13.6 to 24.3 percent; in the Spanish Primera Division, it rose from 19.6 to 38.6 percent; in the Italian Serie A, the increase was from 15.4 to 33.6 percent; and in the German Bundesliga, the jump was from 25.2 to 53.6 percent.

By considering the proportion of foreign players in the squads of some currently dominant European clubs, the picture is even more drastic. For example, 91.7 percent of those who play for Arsenal F.C. are foreign. Additionally, 85.2 percent of the Internazionale Milano FC, 85.2 percent of the Liverpool F.C., 74.1 percent of the Chelsea F.C., and 62.5 percent of the Real Madrid squads are foreign players. ${ }^{4}$ After the Bosmon ruling, similar trends are observable in other types of sports in Europe as well. From the 1994-95 season to the 2001-02 season, the proportion of foreign players in basketball increased from 17.1 to 39 percent; it increased from 12.1 to 40.1 percent in handball, and from 10.2 to 59 percent in ice hockey. These figures from professional sports are in stark contrast to the general proportion of the foreign work force in the European Union. On average, only 6.3 percent workers in the EU-25 are from foreign countries. ${ }^{5}$

The UEFA argues that these changes in the proportion of foreign players who play in the European football leagues could have severe, detrimental effects on the "competitive balance in the national leagues, the training and development of young players and the quality of, and competition between national teams." After the abolition of the foreigner restriction, affluent clubs could take advantage of the freely available foreign players to increase their own strength, which, in turn, could create a distortion in sporting

\footnotetext{
${ }^{1}$ Fédération Internationale de Football Association

${ }^{2}$ Union des Associations Européennes de Football

${ }^{3}$ In general, the macroeconomic effects of hosting a mega-event are estimated to be rather small or negligible and the measured positive effects are concentrated on some specific sectors like beer brewing and tourism (e.g., Szymanski 2002). The intangible welfare effects, on the other hand, are considered to be the dominant positive effects (e.g., Heyne and Suessmuth, 2007).

${ }^{4}$ See CIES (2008).

${ }^{5}$ See INEA (2008).
} 
competition by impeding the smaller clubs from entering the top group. Moreover, the incentives to invest in the development of young, regional talent decrease because clubs can recruit fully trained players, often for less money, from other countries.

The UEFA reacted to this development and proposed the so-called "homegrown rule" to its 52 national member associations during its congress held in Tallin on April 21, 2005. Football clubs taking part in UEFA club competitions, like the UEFA Champions League or the UEFA Cup Matches, had to include six locally trained players in their 25-player squad for the 2007-08 season. According to UEFA regulations, a "locally trained" player is either a club-trained player or an association-trained player. A "club-trained" player is a player who, regardless of his nationality or age, has been registered with his current club for a period of three entire seasons between the age of 15 and 21. The requirements for an "association-trained" player are the same except that the player only must have been registered with any club affiliated with the same national association of his current club. The rule requires that, of the six "locally trained" players, at least three of them must be "club-trained". This requirement was increased by two players in the subsequent season so that by the start of the 2008-09 season, the minimum number of "locally trained players" required per club was eight with at least four "club-trained" players.

Although the ruling does not apply yet to domestic competitions, UEFA is encouraging its members to impose identical quotas in their own national competitions too. According to UEFA, the "training and development of young players is of crucial importance to the future of football. Every football club in every national football association should play a part in this process". In 2008, based on an independent study, ${ }^{6}$ the European Commission formally endorsed UEFA's "homegrown rule", subject to a review of their practical consequences by 2012. According to the Commission, the proposed rule sets a quota of locally trained players at clubs, but it does not discriminate based on nationality; thus, the rule complies with the principle of free movement of workers while promoting the training of young European players.

Before proceeding to the model, we present a short overview of the relevant literature. Simmons (1997) shows that the average contract length of professional football players has significantly increased since the Bosman ruling. Antonioni and Cubbin (2000) analyze the economic effect of the Bosman ruling. Based on empirical evidence and the theory of real options, they support Simmons' result. Moreover, they argue that the Bosman ruling had little effect on player salaries, investment into human capital, or transfer activity. They attribute the rise in salaries to increasing television revenues. Feess and Muehlheusser (2003) compare the Pre-Bosman regime, the Bosman regime, and the Monti regime with respect to contract length, training, and effort incentives. They argue that the prohibition of transfer restrictions reallocates bargaining power from a player's current club to potential new clubs. This reallocation of bargaining power reduces the current club's incentive to invest in the player's human capital, because the current club has to bear the investment costs without being able to appropriate all the investment benefits if the player transfers to a new club. Their paper shows that the different regimes only differ with respect to the contract length. Based on a bargaining model with stochastic player productivity, Dietl et al. (2008) show that football players may benefit from more restrictive transfer rules. The right to charge transfer fees enables clubs to insure their players, and the players, in turn, benefit by converting risky future income into riskless current income.

To the best of our knowledge, our paper is the first to analyze the general implications of a restriction in foreign talent on clubs' investment behaviour. We provide a theoretical model based on contest theory and analyze the effect of such a foreigner rule on the investment behaviour of profit-maximizing clubs in a professional team sports league. More precisely, we investigate the impact on competitive balance, the wage level of the players, and club profits. Our model shows that a league with a binding restriction on foreign talent for all clubs (Regime B) is characterized through a higher degree of competitive balance than a league without a binding restriction on foreign talent (Regime A). Moreover, the wage level of domestic (foreign) talent is higher (lower) in Regime B than in Regime A. Finally, a more restrictive foreigner rule increases profits of all clubs.

\footnotetext{
${ }^{6}$ See Ineum Consulting (2008).
} 


\section{MODEL SPECIFICATION}

The following contest model describes the investment behaviour of profit-maximizing clubs in a professional team sports league. We consider a two-club league where each club $i=1,2$ invests independently in playing talent in order to maximize its own profits. ${ }^{7}$

Our league features the possibility to invest in both domestic talent and foreign talent, whereby $x_{i}$ and $y_{i}$ represent the units of domestic and foreign talent, respectively. Both domestic and foreign talent is measured in perfectly divisible units that can be hired in a competitive labour market. We assume that domestic talent $x_{i}$ and foreign talent $y_{i}$ are combined in each club $i$ via a function $h_{i}\left(x_{i}, y_{i}\right)$ with

$\frac{\partial h_{i}\left(x_{i}, y_{i}\right)}{\partial x_{i}}>0, \frac{\partial^{2} h_{i}\left(x_{i}, y_{i}\right)}{\partial x_{i}^{2}}<0$ and $\frac{\partial h_{i}\left(x_{i}, y_{i}\right)}{\partial y_{i}}>0, \frac{\partial^{2} h_{i}\left(x_{i}, y_{i}\right)}{\partial y_{i}^{2}}<0$

The wage levels per unit of domestic and foreign players are denoted by $c_{x}>0$ and $c_{y}>0$, respectively. Thus, aggregate investment costs for domestic and foreign talent are given for club $i$ by $c_{i}\left(x_{i}, y_{i}\right)=c_{x} x_{i}+c_{y} y_{i} \cdot{ }^{8}$

We introduce a foreigner rule in our model which limits the number of foreign players each club can have. We therefore assume that the amount of foreign talent that club $i$ can hire is limited by a constant $\theta>0$.

The contest success function (CSF) maps the vector of talent investment into the winning probabilities $w_{i}$ for each club. We apply the logit approach, which is the most widely used functional form of a CSF in sporting contests, ${ }^{9}$ yielding the following win percentage of club $i$

$$
w_{i}(x, y)=\frac{h_{i}\left(x_{i}, y_{i}\right)}{h_{i}\left(x_{i}, y_{i}\right)+h_{j}\left(x_{j}, y_{j}\right)}, i, j=1,2 \text { and } i \neq j \text {, }
$$

where $x$ and $y$ are vectors of all clubs' domestic and foreign talent, respectively; i.e., $x=\left(x_{i}, x_{j}\right)$ and $y=\left(y_{i}, y_{j}\right)$.

We further assume that the supply of talent for both domestic talent and foreign talent is flexible. Thus, the number of talent hired by club $i$ has no influence on the talent pool that is available to the other club $j$. In this case, a club can sign additional (domestic and foreign) talent without decreasing the number of (domestic and foreign) talent in other clubs that compete in the same league; i.e., $\frac{\partial x_{i}}{\partial x_{j}}=0$ and $\frac{\partial y_{i}}{\partial y_{j}}=0$. A non-fixed pool of talent can easily be justified in the European football leagues. Especially after the Bosman verdict in 1995 which established an international players market. ${ }^{10}$

The revenue function of club $i$ is given by $R_{i}\left(w_{i}(x, y), m_{i}\right)$ and is assumed to have the following

\footnotetext{
${ }^{7}$ For an analysis about the impact of the clubs' objective function, see e.g., Fort and Quirk (2004), Vrooman (2000, 2008) and Dietl et al. (2009).

${ }^{8}$ For the sake of simplicity, we do not take into account other than labour costs and normalize the fixed capital cost to zero. See Vrooman (1995) for a more general cost function where clubs have different marginal costs or Késenne (2007) for a cost function with a fixed capital cost.

${ }^{9}$ The logit CSF was generally introduced by Tullock (1980) and later was axiomatised by Skaperdas (1996) and Clark and Riis (1998). An alternative functional form would be the probit CSF (e.g., Lazear and Rosen, 1981; Dixit, 1987) or the difference-form CSF (e.g., Hirshleifer, 1989).

${ }^{10}$ The conventional approach to model the closed U.S. player market is to assume a fixed talent supply, together with Walrasian conjectures. This, however, does not constitute a Nash equilibrium as emphasized by Szymanski (2003b).
} 
properties: ${ }^{11}$ either $\frac{\partial R_{i}}{\partial w_{i}}>0$ and $\frac{\partial^{2} R_{i}}{\partial w_{i}^{2}} \leq 0$ for all $w_{i} \in[0,1]$ or $\exists w_{i}^{*} \in[0,1]$ such that if $w_{i} \geq w_{i}^{*}$, then $\frac{\partial R_{i}}{\partial w_{i}}<0$, otherwise $\frac{\partial R_{i}}{\partial w_{i}}>0$, and $\frac{\partial^{2} R_{i}}{\partial w_{i}^{2}} \leq 0$ everywhere. The parameter $m_{i}>0$ represents the market size of club $i$. Without loss of generality, we assume that club 1 is the "large-market" club and club 2 is the "small-market" club. The large club generates higher revenues for a given win percentage than the small club. Since we consider a two-club league, we can normalize the market size of the small club to unity and write $m$ instead of $m_{1}$ such that $m_{1}=m>m_{2}=1$.

The profit function of club $i$, denoted $\pi_{i}$, is given by revenues minus costs

$\pi_{i}\left(w_{i}\right)=R_{i}\left(w_{i}(x, y), m_{i}\right)-c_{i}\left(x_{i}, y_{i}\right)$.

Club $i=1,2$ chooses an investment level of playing talent such that its own profits $\pi_{i}$ are maximized subject to a constraint for the foreign talent. The constraint represents the foreigner rule, which implies that the number of foreign players in club $i$ must not exceed a given threshold value $\theta$. Hence, club $i$ has to solve the following maximization problem

$\max _{x_{i} \geq 0, y_{i} \geq 0} \pi_{i}\left(w_{i}(x, y), m_{i}\right) \quad$ s.t. $\quad y_{i} \leq \theta$.

\section{RESULTS}

To make further progress and to derive closed form solutions, we choose specific functional forms for the $h$ function and the revenue function. First, we assume that domestic and foreign talent are combined in each club via a Cobb-Douglas function; i.e., $h_{i}\left(x_{i}, y_{i}\right)=x_{i}^{\alpha} y_{i}^{\beta}$ where $\alpha>0$ and $\beta>0$ are parameters determining the relative strength of domestic and foreign talent, respectively. Second, we assume that the revenue function of club $i$ is linear in its own win percentage with $R_{i}\left(w_{i}(x, y), m_{i}\right)=w_{i}(x, y) m_{i}{ }^{12}$

We derive the following first-order conditions

$$
\begin{gathered}
\frac{\alpha x_{i}^{\alpha-1} y_{i}^{\beta} x_{j}^{\alpha} y_{j}^{\beta}}{\left(x_{i}^{\alpha} y_{i}^{\beta}+x_{j}^{\alpha} y_{j}^{\beta}\right)^{2}} m_{i}-c_{x} \leq 0, x_{i}\left(\frac{\alpha x_{i}^{\alpha-1} y_{i}^{\beta} x_{j}^{\alpha} y_{j}^{\beta}}{\left(x_{i}^{\alpha} y_{i}^{\beta}+x_{j}^{\alpha} y_{j}^{\beta}\right)^{2}} m_{i}-c_{x}\right)=0, \\
\frac{\beta x_{i}^{\alpha} y_{i}^{\beta-1} x_{j}^{\alpha} y_{j}^{\beta}}{\left(x_{i}^{\alpha} y_{i}^{\beta}+x_{j}^{\alpha} y_{j}^{\beta}\right)^{2}} m_{i}-c_{y}-\lambda_{i} \leq 0, y_{i}\left(\frac{\beta x_{i}^{\alpha} y_{i}^{\beta-1} x_{j}^{\alpha} y_{j}^{\beta}}{\left(x_{i}^{\alpha} y_{i}^{\beta}+x_{j}^{\alpha} y_{j}^{\beta}\right)^{2}} m_{i}-c_{y}-\lambda_{i}\right)=0, \\
y_{i}-\theta \geq 0, \lambda_{i}\left(y_{i}-\theta\right)=0
\end{gathered}
$$

for $i, j=1,2$ and $i \neq j . \lambda_{i}$ are Lagrange multipliers.

To characterize the equilibrium, we have to distinguish different regimes depending on whether the foreigner rule is binding or not. ${ }^{13}$

\footnotetext{
${ }^{11}$ See Szymanski and Késenne (2004).

${ }^{12}$ This concave revenue function has the desired properties and is consistent with the revenue function in, e.g., Hoehn and Szymanski (1999), Szymanski (2003a), Szymanski and Késenne (2004), Vrooman (2007) and Dietl and Lang (2008). Our results, however, are also robust with respect to a quadratic revenue function.

${ }^{13}$ See also Dietl et al. (2009).
} 


\subsection{Regime A: The foreign player rule is ineffective for both clubs}

In this section, we consider the benchmark case in which the foreigner rule is ineffective for both clubs; i.e., the constraint for foreign talent is not binding.

In Regime A, the equilibrium demand of club $i=1,2$ for domestic and foreign talent is computed from the first-order conditions (4) as

$$
\left(x_{i}^{A}, y_{i}^{A}\right)=\left(\frac{\alpha m^{\alpha+\beta} m_{i}}{c_{x}\left(m^{\alpha+\beta}+1\right)^{2}}, \frac{\beta m^{\alpha+\beta} m_{i}}{c_{y}\left(m^{\alpha+\beta}+1\right)^{2}}\right),
$$

with $m_{1}=m$ and $m_{2}=1$.

We derive that, without a binding restriction on foreign talent, the large-market club demands a higher amount of both domestic and foreign talent in equilibrium; i.e., $x_{1}^{A}>x_{2}^{A}$ and $y_{1}^{A}>y_{2}^{A}$ since $m>1$. This is due to the fact that the marginal revenue of talent investments is higher for the large club. Moreover, the talent investment in domestic (foreign) talent is increasing in its effectiveness parameters $\alpha$ and $\beta$.

Thus, we are in Regime A if, in equilibrium, the constraint $\theta$ for foreign talent does not bind for the large-market club; i.e., if $\theta \in I^{A}=\left(\theta_{1}, \infty\right)$, where $\theta_{1}=y_{1}^{A}$.

The aggregate demand for domestic and foreign talent is given by

$$
x^{A}=x_{1}^{A}+x_{2}^{A}=\frac{\alpha(m+1) m^{\alpha+\beta}}{c_{x}\left(m^{\alpha+\beta}+1\right)^{2}} \text { and } y^{A}=y_{1}^{A}+y_{2}^{A}=\frac{\beta(m+1) m^{\alpha+\beta}}{c_{y}\left(m^{\alpha+\beta}+1\right)^{2}} \text {. }
$$

The equilibrium wage level of the players is determined in the labour market. We assume that the supply of domestic and foreign talent is given by $s_{x} c_{x}$ and $s_{y} c_{y}$, respectively, with $s_{x}, s_{y}>0$. By equating supply and demand and solving for the players' equilibrium wage level $\left(c_{x}, c_{y}\right)$, we derive

$$
c_{x}^{A}=\left(\frac{\alpha(m+1) m^{\alpha+\beta}}{s_{x}\left(m^{\alpha+\beta}+1\right)^{2}}\right)^{1 / 2} \text { and } c_{y}^{A}=\left(\frac{\beta(m+1) m^{\alpha+\beta}}{s_{y}\left(m^{\alpha+\beta}+1\right)^{2}}\right)^{1 / 2} .
$$

Plugging the equilibrium demand (5) into the CSF (1), we derive the following equilibrium win percentages of club $i=1,2$

$$
\left(w_{1}^{A}, w_{2}^{A}\right)=\left(\frac{m^{\alpha+\beta}}{m^{\alpha+\beta}+1}, \frac{1}{m^{\alpha+\beta}+1}\right) .
$$

It is clear that the large club is the dominant team, which has a higher win percentage in equilibrium than the small club, i.e., $w_{1}^{A}>w_{2}^{A}$.

The difference in win percentage measures the degree of competitive balance $C B$ in the league which is given by 
$C B^{A}=w_{1}^{A}-w_{2}^{A}=\frac{m^{\alpha+\beta}-1}{m^{\alpha+\beta}+1}$.

Note that a more balanced league is characterized by a lower value of $C B$. Thus, a fully balanced league yields $C B=0$.

We conclude that, in Regime A, the clubs' profits given by $\pi_{i}^{A}\left(w_{i}\right)$ do not depend on the wage level and, hence, not on the parameters $s_{y}$ and $s_{x}$. This result is due to the Cobb-Douglas formulation in the CSF: every percentage change in the players' wage level leads to an equal percentage change in the number of talent hired, and thus the total amount spent on talent remains constant.

\subsection{Regime $B$ : The foreigner rule is effective for both clubs}

In Regime $\mathrm{B}$, we assume that the foreigner rule is effective for both clubs. In other words, the constraint on foreign talent $\theta$ is binding for both clubs. This is true if $\theta \in I^{B}=\left(0, \theta_{2}\right]$. The definite size of $\theta_{2}$ depends on how the small club reacts to the introduction of the foreigner restriction in Regime C.

In Regime $\mathrm{B}$, the equilibrium demand of club $i=1,2$ for domestic and foreign talent is computed from the first-order conditions (4) as

$\left(x_{i}^{B}, y_{i}^{B}\right)=\left(\frac{\alpha m^{\alpha} m_{i}}{c_{x}\left(m^{\alpha}+1\right)^{2}}, \theta\right)$,

with $m_{1}=m$ and $m_{2}=1$. Again, the large club demands more domestic talent than the small club; i.e., $x_{1}^{B}>x_{2}^{B}$ since $m>1$.

Aggregate demand for domestic and foreign talent, respectively, is given by

$x^{B}=x_{1}^{B}+x_{2}^{B}=\frac{\alpha(m+1) m^{\alpha}}{c_{x}\left(m^{\alpha}+1\right)^{2}}$ and $y^{B}=y_{1}^{B}+y_{2}^{B}=2 \theta$.

The equilibrium wage level of the players is determined on the labour market as

$c_{x}^{B}=\left(\frac{\alpha(m+1) m^{\alpha}}{s_{x}\left(m^{\alpha}+1\right)^{2}}\right)^{1 / 2}$ and $c_{y}^{B}=\frac{2 \theta}{s_{y}}$.

By plugging the equilibrium demand for domestic and foreign talent into (1), we derive the equilibrium win percentage of club $i$ as

$$
\left(w_{1}^{B}, w_{2}^{B}\right)=\left(\frac{m^{\alpha}}{m^{\alpha}+1}, \frac{1}{m^{\alpha}+1}\right),
$$

so that competitive balance in Regime $\mathrm{B}$ becomes

$$
C B^{B}=w_{1}^{B}-w_{2}^{B}=\frac{m^{\alpha}-1}{m^{\alpha}+1} .
$$


We derive the following proposition:

\section{Proposition 1}

A more restrictive foreigner rule, i.e., a lower value of $\theta$, increases the profits of both clubs, whereas it decreases the wage level for foreign players.

Proof: Straightforward and therefore omitted.

The intuition for this result is that a tighter restriction on foreign talent reduces the negative externality the clubs impose on each other when hiring another unit of talent. Due to the contest structure, both teams can lower their investment in domestic or foreign talent by $k$ percent without changing the win percentages. This lowers costs, while leaving the revenues unchanged.

We see that the equilibrium demand for domestic talent $x_{i}^{B}$ of club $i$ is independent of the restriction $\theta$ on the amount of foreign talent. As a consequence, the equilibrium wage level $c_{x}^{B}$ for domestic talent is also unaffected by changes in $\theta$. Moreover, both clubs adapt their equilibrium demand $y_{i}^{B}$ for foreign talent due to variations of $\theta$ in the same way; i.e., $\frac{\partial y_{1}^{B}}{\partial \theta}=\frac{\partial y_{2}^{B}}{\partial \theta}$. It follows that the equilibrium win percentages $\left(w_{1}^{B}, w_{2}^{B}\right)$ of both clubs and the competitive balance $C B^{B}$ in Regime $\mathrm{B}$ remain unchanged across variations in $\theta$. Furthermore, the revenues of both clubs are also unaffected. In contrast, the equilibrium demand $y_{i}^{B}$ for foreign talent decreases with a lower value of $\theta$, which implies a lower wage level for foreign players in equilibrium. It directly follows that profits of both clubs increase since revenues stay equal and costs decrease.

\subsection{Comparison of Regimes A and B}

In this section, we derive more insights regarding the effect of a foreigner rule by comparing Regimes $\mathrm{A}$ and $\mathrm{B}$. That is, we compare a league without a (binding) restriction on foreign talent with a league that has implemented an effective foreigner rule for both clubs. We derive the following results:

\section{Proposition 2}

(i) The equilibrium demand and wage level of domestic (foreign) talent is higher (lower) in Regime B than in Regime A .

(ii) The introduction of a foreigner rule, i.e., a binding restriction on the amount of foreign talent, increases competitive balance.

Proof: See Appendix.

The first part of the proposition shows that the introduction of a foreigner rule decreases the wage level of foreign players. Intuitively, this is clear since the aggregate demand for foreign players decreases in the transition from Regime A to Regime B; i.e., $y^{A}>y^{B}$. Thus, the market clearing price $c_{y}$ for foreign talent must decrease accordingly. In contrast, each club will demand more domestic talent in a league with a binding restriction on foreign talent. In other words, aggregate demand for domestic talent is higher in Regime B compared to Regime A; i.e., $x^{A}<x^{B}$. It also follows that the wage level for domestic talent will increase in the transition from Regime A to Regime B.

The second part of the proposition states that the introduction of the foreigner restriction increases competitive balance. This is because the large club is more severely handicapped by the restriction on 
foreign talent than the small club. ${ }^{14}$ Hence, the win percentage of the large club will decrease, and the win percentage for a small club will increase, in the transition from Regime A to Regime B. As a consequence, a binding foreigner rule is beneficial for the competitive balance in the league. Moreover, the large club's revenue decreases and the small club's revenue increases. The effect on clubs' profits, however, is ambiguous and depends on the parameter constellation.

\subsection{Regime $C$ : The foreigner rule is only effective for the large-market club}

In Regime $\mathrm{C}$, we assume that the foreigner rule is only effective for the large-market club; i.e., the restriction on foreign talent is only binding for club 1 . Thus, we are in Regime $\mathrm{C}$ if $\theta \in I^{C}=\left(\theta_{2}, \theta_{1}\right]{ }^{15}$

The equilibrium demand of club $i=1,2$ for domestic and foreign talent is computed from the first-order conditions (4) as ${ }^{16}$

$$
\begin{aligned}
& \left(x_{1}^{C}, y_{1}^{C}\right)=\left(\frac{\alpha m c_{y}}{c_{x}}\left(\sqrt{\frac{m^{\alpha} \theta}{c_{y}}}-m^{\alpha} \theta\right), \theta\right) \\
& \left(x_{2}^{C}, y_{2}^{C}\right)=\left(\frac{\alpha c_{y}}{c_{x}}\left(\sqrt{\frac{m^{\alpha} \theta}{c_{y}}}-m^{\alpha} \theta\right), \sqrt{\frac{m^{\alpha} \theta}{c_{y}}}-m^{\alpha} \theta\right)
\end{aligned}
$$

Again, the large club has a higher demand for both domestic and foreign talent in equilibrium. Aggregate demand for domestic and foreign talent is given by

$$
\begin{aligned}
& x^{C}=x_{1}^{C}+x_{2}^{C}=\frac{(m+1) \alpha c_{y}}{c_{x}}\left(\sqrt{\frac{m^{\alpha} \theta}{c_{y}}}-m^{\alpha} \theta\right), \\
& y^{C}=y_{1}^{C}+y_{2}^{C}=\theta+\sqrt{\frac{m^{\alpha} \theta}{c_{y}}}-m^{\alpha} \theta .
\end{aligned}
$$

By plugging the equilibrium demand for domestic and foreign talent into (1), we derive the win percentage in Regime $\mathrm{C}$ as

$$
\left(w_{1}^{C}, w_{2}^{C}\right)=\left(\sqrt{c_{y} m^{\alpha} \theta}, 1-\sqrt{c_{y} m^{\alpha} \theta}\right) .
$$

Since the large club demands more of both domestic and foreign talent, we derive that this club also has a higher win percentage in equilibrium. Competitive balance in Regime $\mathrm{C}$ is then given by

\footnotetext{
${ }^{14}$ Remember that the large club demands a higher amount of foreign talent in Regime A; i.e., $y_{1}^{A}>y_{2}^{A}$.

${ }^{15}$ We present this regime for the sake of completeness. Regime C, however, is not likely to be effective since, e.g., the UEFA plans to implement a foreigner rule which is binding for both small and large clubs.

${ }^{16}$ Note that we have to restrict our analysis in Regime $\mathrm{C}$ to the special case where $\beta=1$ and talent supply is completely elastic. Otherwise, the first-order conditions (4) can not be solved analytically. Moreover, we assume that $1>m^{\alpha} \theta c_{y}$. In the next section we provide a numerical example in order to show that the results we derive for this special case also carry over to the general case.
} 
$C B^{C}=w_{1}^{C}-w_{2}^{C}=2 \sqrt{c_{y} m^{\alpha} \theta}-1>0$.

We derive the following results:

\section{Proposition 3}

In Regime $C$, a more restrictive foreigner rule, i.e., a lower value of $\theta$, increases the demand for domestic talent for both clubs and increases (decreases) the demand for foreign talent for the small (large) club. Moreover, the corresponding effect on competitive balance is positive.

Proof: See Appendix.

The proposition shows that a tighter restriction on foreign talent, which is only binding for the large club, induces both clubs to substitute some of the lost talent with domestic talent. Moreover, the small club will also increase its demand for foreign talent. ${ }^{17}$ It follows that, as the regulation becomes more restrictive, i.e., as $\theta$ decreases, the league becomes more balanced. As a consequence, the small club's revenue increases, and the large club's revenue decreases. Given constant player wages, total costs decrease for the small club and thus its profit increases. The large club will save on foreign players but faces decreasing revenue and increasing expenditure for domestic players, which makes the total effect on the large club's profit undetermined.

\subsection{Numerical Simulation}

To illustrate the effect of restriction on foreign talent, we provide a numerical simulation that summarizes our main results. Remember that Regime A is effective if $\theta \in\left(\theta_{1}, \infty\right)=\left(y_{1}^{A}, \infty\right)$, whereas Regime $\mathrm{B}$ is active for $\theta \in\left(0, \theta_{2}\right]$, and Regime $\mathrm{C}$ for $\theta \in\left(\theta_{2}, \theta_{1}\right]$. Also recall that a lower value of the parameter $\theta$ characterizes a tighter restriction on foreign players.

The upper part of Figure 1 depicts competitive balance $C B=w_{1}-w_{2}$ as a function of the parameter $\theta$ and shows that competitive balance increases in the transition from Regime A to Regime $\mathrm{B} .{ }^{18}$

The lower part of Figure 1 depicts the aggregate demand for domestic talent $x_{1}+x_{2}$ and foreign talent $y_{1}+y_{2}$ as functions of the parameter $\theta$. It illustrates that, in the transition from Regime A to Regime $\mathrm{B}$, the aggregate demand for domestic talent increases while the aggregate demand for foreign talent decreases.

Figure 2 depicts the profits $\pi_{1}$ of the large club and the profits $\pi_{2}$ of the small club as functions of the parameter $\theta$. The figure shows that profits of the small club increase in the transition from Regime A to Regime $\mathrm{B}$. The profits of the large club, however, decrease in Regime $\mathrm{C}$ and then increase again in Regime $B$. In addition, the figure shows that it is undetermined whether the profits of the large club are higher in Regime A or in Regime B.

\footnotetext{
${ }^{17}$ This implies that $\theta_{2}>y_{1}^{A}$.

${ }^{18}$ Note that a lower value of $w_{1}-w_{2}$ indicates a more balanced league.
} 
Figure 1. Effect of foreigner restriction on talent investment and competitive balance
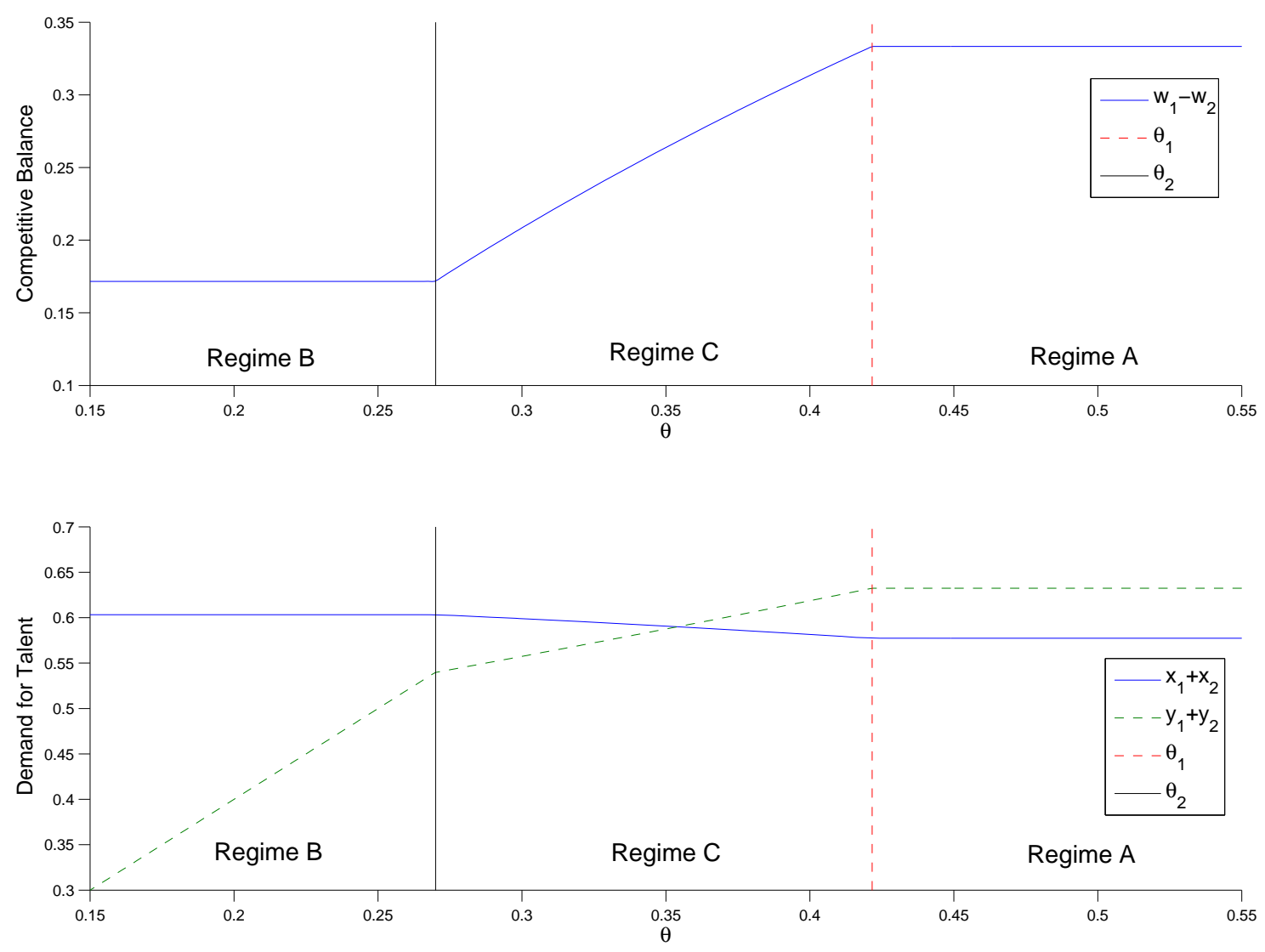

For the numerical exercise, the following parameter values where used: $s_{x}=1, s_{y}=1.2, m=2, \alpha=0.5, \beta=0.5$.

\section{CONCLUSION}

A profitable and balanced domestic sports league that fosters domestic talent not only increases the probability of a successful application for a mega-event, it also crucially increases the prospects of a successful event because multiplier effects can be triggered more easily if the interest of the hosting nation is sustained by a progressing national team.

Increasing dominance by some rich clubs, spiralling wages, and financial instability are the major challenges in European football. In this paper, we have shown that a restriction on foreign players can help to alleviate these problems. Foreign player restrictions promote competitive balance while strengthening the financial situation of small clubs and fostering the development of domestic talent.

Recently, FIFA also proposed a limit on the number of foreign football players. FIFA aims to implement the so-called "6+5 rule", which means that each team must field in the starting "eleven" at least six players eligible for the national team of the club's country. However, there would be no restrictions on the number of foreign substitute players and no limit on the total number of foreigners a club can sign. The proposed 6+5 rule has the backing of 155 of FIFA's 208 member nations, but it has been dismissed as illegal by the European Commission because it discriminates on the basis of nationality and is a restriction on the free movement of workers. 
Figure 2: Effect of foreigner restriction on club profits

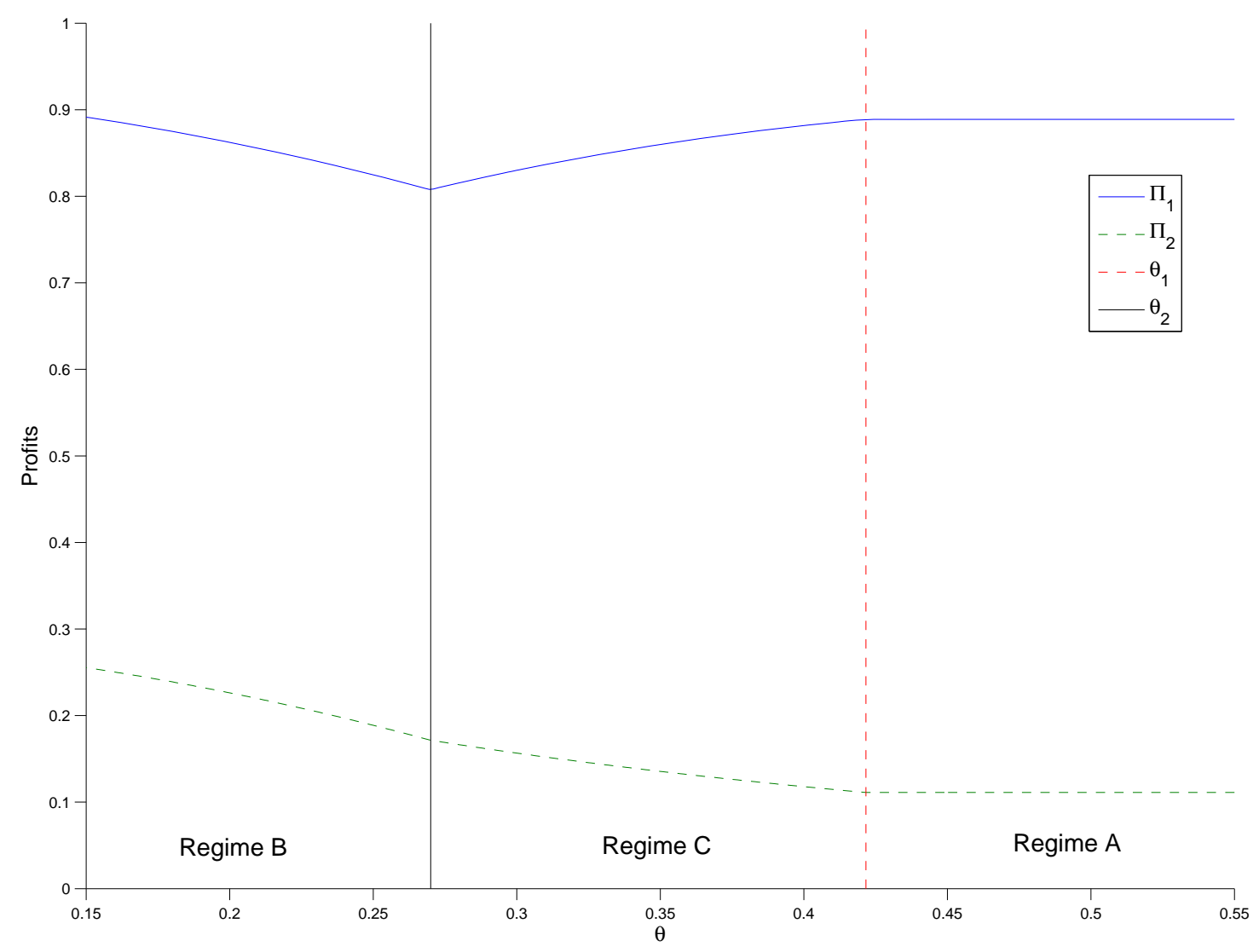

For the numerical exercise, the following parameter values where used: $s_{x}=1, s_{y}=1.2, m=2, \alpha=0.5, \beta=0.5$.

However, a recent report by the "Institute for European Affairs" (INEA) claims that "the $6+5$ rule is in accordance with Art. 151 EC and the new Art. 165 TFU of the Lisbon Treaty, because it reflects the autonomy of sport compared to the purely economic orientations of the fundamental freedoms and the competitive order." Moreover, "the key aim of the $6+5$ rule in the view of the experts is the creation and assurance of sporting competition. The $6+5$ rule does not impinge on the core area of the right to freedom of movement. The rule is merely a rule of the game declared in the general interest of sport in order to improve the sporting balance between clubs and associations." ${ }^{19}$

In the light of our analysis, a system like FIFA's "6+5 rule" also seems to be an appropriate means to alleviate the current problems in most European football leagues. Even though it was deemed to be illegal by the European Court of Justice, the EU should reconsider its decision, acknowledging the peculiarity of the sports industry.

\footnotetext{
${ }^{19}$ See INEA (2008).
} 


\section{APPENDIX}

\section{Proof of Proposition 2}

First, we show that the equilibrium demand and wage level of domestic (foreign) talent is higher (lower) in Regime B than in Regime A. We derive that the aggregate demand for domestic talent in Regime $\mathrm{A}$ and $\mathrm{B}$ after inserting the equilibrium wage is given by

$$
x^{A}=\frac{\left(\alpha(m+1) m^{\alpha+\beta} s_{x}\right)^{1 / 2}}{1+m^{\alpha+\beta}} \text { and } \frac{\left(\alpha(m+1) m^{\alpha} s_{x}\right)^{1 / 2}}{1+m^{\alpha}}=x^{B} .
$$

It can easily be verified that $x^{A}<x^{B}$; i.e., aggregate demand for domestic talent is higher in Regime $\mathrm{B}$ than in Regime A. Moreover, due to the foreigner restriction it is clear that aggregate demand for foreign talent is higher in Regime A than in Regime B; i.e., $y^{A}>y^{B}$. This proves the first part of the proposition.

Second, we show that the introduction of a foreigner rule, i.e., a binding restriction on the amount of foreign talent, increases competitive balance. By comparing competitive balance in Regimes A and B, we derive

$$
C B^{A}>C B^{B} \Leftrightarrow m^{\beta}>1
$$

which is fulfilled for all $m>1$. This proves the second part of the proposition.

\section{Proof of Proposition 3}

First, we show that a more restrictive foreigner rule, i.e., a lower value of $\theta$, increases the demand for domestic talent for both clubs in Regime C. We compute the derivative of $x_{i}^{C}$ with respect to $\theta$ as

$$
\frac{\partial x_{1}^{C}}{\partial \theta}=\frac{\alpha c_{y} m^{\alpha+1}}{c_{x}}\left(\frac{1}{2 w_{1}^{C}}-1\right) \text { and } \frac{\partial x_{2}^{C}}{\partial \theta}=\frac{\alpha c_{y} m^{\alpha}}{c_{x}}\left(\frac{1}{2 w_{1}^{C}}-1\right) \text {. }
$$

We derive that $\frac{\partial x_{1}^{C}}{\partial \theta}<0$ and $\frac{\partial x_{2}^{C}}{\partial \theta}<0$ since $w_{1}^{C}>\frac{1}{2}$. That is, both clubs increase their demand for domestic talent through a lower value of $\theta$, which proves the claim.

Second, we show that a more restrictive foreigner rule increases (decreases) the demand for foreign talent for the small (large) club in Regime C. The derivative of $y_{i}^{C}$ with respect to $\theta$ is given by

$$
\frac{\partial y_{1}^{C}}{\partial \theta}=1 \text { and } \frac{\partial y_{2}^{C}}{\partial \theta}=m^{\alpha}\left(\frac{1}{2 w_{1}^{C}}-1\right)<0 \text {, }
$$

which proves the claim.

Finally, we show that a more restrictive foreigner rule increases competitive balance in Regime C. We compute the derivative of $C B^{C}$ with respect to $\theta$ as

$$
\frac{\partial C B^{C}}{\partial \theta}=\sqrt{\frac{c_{y} m^{\alpha}}{\theta}}>0 .
$$

It follows that competitive balance increases and the league becomes more balanced through a more restrictive foreigner rule. 


\section{REFERENCES}

Antonioni, P. and J. Cubbin, 2000, “The Bosman Ruling and the Emergence of a Single Market in Soccer Talent,” European Journal of Law and Economics, 9, 157-173.

CIES, 2008, "Demographic Study of Footballers in Europe.”

Clark, D. and C. Riis, 1998, “Contest Success Functions: An Extension,” Economic Theory, 11, 201-204.

Dietl, H. and M. Lang, 2008, “The Effect of Gate Revenue-Sharing on Social Welfare,” Contemporary Economic Policy, 26, 448-459.

Dietl, H., E. Franck, and M. Lang, 2008, "Why Football Players May Benefit from the "Shadow of the Transfer System”," European Journal of Law and Economics, 26, 129-151.

Dietl, H., M. Lang, and A. Rathke, 2009, “The Effect of Salary Caps in Professional Team Sports on Social Welfare,” The B.E. Journal of Economic Analysis and Policy, 9, Article 17.

Dietl, H., M. Lang, and S. Werner, 2009, "Social Welfare in Sports Leagues with Profit-Maximizing and/or Win-Maximizing Clubs,” Southern Economic Journal (forthcoming).

Dohmen, T., A. Falk, D. Huffman and U. Sunde, 2006, "Seemingly Irrelevant Events Affect Economic Perceptions and Expectations: The FIFA World Cup 2006 as a Natural Experiment”, Institute for the Study of Labor Working Paper.

Dixit, A., 1987, “Strategic Behavior in Contests,” American Economic Review, 77, 891-898.

Feess, E. and G. Muehlheusser, 2003, “Transfer Fee Regulations in European Football,” European Economic Review, 47, 645-668.

Fort, R. and J. Quirk, 2004, “Owner Objectives and Competitive Balance,” Journal of Sports Economics, 5, $20-32$.

Heyne, M., W. Maennig and B. Suessmuth, 2008, “Mega Sporting Events as Experience Goods,” Working Paper.

Heyne, M. and B. Suessmuth, 2007, "Hidden Value: Wohlfahrtsoekonomische Effekte internationaler Sportgrossveranstaltungen. Eine Betrachtung vom anderen Ende des Contingent-Valuation-Spektrums: Maradona-vs. Beckenbauer-Effekt,” Schmollers Jahrbuch, 127, 511-529.

Hirshleifer, J., 1999, “Conflict and Rent-Seeking Success Functions: Ratio Vs. Difference Models of Relative Success,” Public Choice, 63, 101-112.

Hoehn, T. and S. Szymanski, 1999, “The Americanization of European Football,” Economic Policy, 14, 204-240.

INEA, 2008, "Expert Opinion on the Compatibility of the "6+5 Rule” with European Community Law."

Ineum Consulting, 2008, “Home grown player rule.”

Késenne, S., 2007, The Economic Theory of Professional Team Sports - An Analytical Treatment, Cheltenham, UK: Edward Elgar.

Lazear, E. and S. Rosen, 1981, “Rank-Order Tournaments as Optimum Labor Contracts,” Journal of Political Economy, 89, 841-864.

Raetzel, S. and J. Weimann, 2006, “Der Maradona Effekt: Wie viel Wohlfahrt schafft die deutsche Nationalmannschaft?“ Perspektiven der Wirtschaftspolitik, 7, 257-270.

Simmons, R., 1997, “Implications of the Bosman Ruling for Football Transfer Markets,” Economic Affairs, $17,13-18$.

Skaperdas, S., 1996, “Contest Success Functions,” Economic Theory, 7, 283-290.

Szymanski, S., 2002, “The Economic Impact of the World Cup,” World Economics, 3, 169-177. 
Szymanski, S., 2003, “The Economic Design of Sporting Contests,” Journal of Economic Literature, 41, 1137-1187.

Szymanski, S. and S. Késenne, 2004, “Competitive Balance and Gate Revenue Sharing in Team Sports,” The Journal of Industrial Economics, 52, 165-177.

Tullock, G., 1980, “Efficient Rent-Seeking,” in J.M. Buchanan, R.D. Tollison, and G. Tullock, eds., Toward a Theory of Rent Seeking Society, Texas: University Press, 97-112.

Vrooman, J., 1995, “A General Theory of Professional Sports Leagues,” Southern Economic Journal, 971-990.

Vrooman, J., 2000, “The Economics of American Sports Leagues,” Scottish Journal of Political Economy, 2000, 47, 364-398.

Vrooman, J., 2007, “Theory of the Beautiful Game: The Unification of European Football,” Scottish Journal of Political Economy, 54, 314-354.

Vrooman, J., 2008, “Theory of the Perfect Game: Competitive Balance in Monopoly Sports Leagues,” Review of Industrial Organization, 31, 1-30. 